\title{
Thermo-Analytical Techniques on MX-80 Montmorillonite: A Way to Know the Behavior of Water and its Thermodynamic Properties during Hydration - Dehydration Processes
}

\author{
Vieillard $\mathrm{PH}^{1 *}$, Tajeddine $\mathrm{L}^{1}$, Gailhanou $\mathrm{H}^{2}$, Blanc $\mathbf{P}^{2}$, Lassin $\mathrm{A}^{2}$ and Gaboreau $\mathbf{S}^{2}$ \\ ${ }^{1}$ CNRS-IC2MP-UMR 7285, 5 ave Albert turpain, TSA 51106, 86073F Poitiers cedex, France \\ ${ }^{2} B R G M, 3$ Av. Claude Guillemin, BP6009, F-45060 Orléans, France
}

\begin{abstract}
Thermoanalytical techniques, including differential thermal analysis (DTA) and thermogravimetric analysis (TGA), are considered as a way to determine the temperature history of concrete after fire exposure. TGA is essentially a means of observing the weight evolution of a sample as a function of temperature (dynamic heating) or time (isothermal heating). In its simplest form, the instrument used consists of a sensitive balance and a furnace arranged such that the sample holder sits inside the furnace. The system includes a thermocouple to monitor the sample temperature and a heating controller to maintain a constant temperature or change the temperature in a pre-determined fashion. DTA compares the temperature of a sample with that of a suitable reference material while both materials are heated at the same rate. Any difference in temperature between the two materials is detected by thermocouples whose signal is proportional to $\Delta \mathrm{T}$. To maintain the sample and reference material under similar conditions, both materials are embedded in a block of material with a large thermal mass. In theory, the temperature change in the sample should be proportional to the enthalpy change.
\end{abstract}

Keywords: MX-80 bentonite; Thermogravimetric analysis; Differential thermal analysis; Adsorption; Desorption; Enthalpy of the dehydration of MX-80; Enthalpy of the formation of water; Hydration; Montmorillonite

\section{Introduction}

The TGA/DTA analysis of clay is an important tool in solving the role of water in reactions involving clays [1]. Recognizing how these materials act and interact as environmental conditions change requires a clear understanding of the thermodynamics of these materials. The adsorption of water molecules on clays has been studied using various experimental techniques, including X-ray diffraction thermogravimetric analysis and adsorption isotherms [2-5]. However, in terms of water adsorption, the results of these techniques are particularly difficult to interpret because, as adsorption proceeds, all porosity scales are relevant. Furthermore, particles and aggregates break up into smaller units and generate new void spaces. Studies of water adsorption in montmorillonites provide evidence of the structure of the clay-water complex, which depends strongly on the exchangeable cations as well as the clay/water ratio. The hydration process of clay sheets is very complex. In principle, three types of hydration can be distinguished: (a) interlayer: limited to interlayer spaces and associated with the hydration of the exchangeable cations; (b) continuous or osmotic, which includes both interlayer spaces and external surfaces, as is the case of montmorillonite; (c) and the capillary condensation of free water, which fills up the micropores existing in inter- and intra-aggregates. Interlayer hydration includes the hydration of ions, the polarization of water molecules by cations, interaction with the silicate surfaces, the activity of the water in that system, and the size and morphology of clay particles and the spatial distribution between particles [6-11].

Some of these studies report findings related to well-defined homoionic montmorillonites and their adsorption-desorption isotherms involving water vapor [12,13] as well as related heats of adsorption $[14,15]$. However, there is insufficient knowledge of the hydration-dehydration mechanism for smectite / water or, more specifically, the structural and thermodynamic features of smectites as a function of hydration. Gailhanou et al. $[16,17]$ have studied the standard enthalpy of formation $\left(\Delta_{\mathrm{f}} \mathrm{H}_{0}\right)$, entropy $\left(\mathrm{S}_{0}\right)$, and heat capacity of smectite MX-80, illite IMt-2, and illite/smectite ISCz-1 using lowtemperature adiabatic calorimetry for both the hydrated and anhydrous phases. Nevertheless, this previous set of thermodynamic properties is incomplete, and no data can be found in the literature describing the dehydration enthalpies corresponding to the different stages of hydration of the entire alkali series of homoionic montmorillonites.

In the present study, simultaneous TGA/DTA analyses were conducted over a range of temperatures and $\mathrm{H}_{2} \mathrm{O}$ vapor pressures to better understand the hydration-dehydration behavior of natural bentonite MX-80 and to determine the partial and integral molar enthalpies of dehydration.

\section{Materials and Method}

The bentonite clay (MX-80) from Wyoming, USA, chosen for this study as an example of a possible future backfill material [18] is a mixed $\mathrm{Na} / \mathrm{Ca}$ montmorillonite with a predominant presence of $\mathrm{Na}$. This material also contains associated minerals, such as quartz, K-feldspars, carbonates, and micas.

The present work was performed on the clay fraction $\leq 2 \mu \mathrm{m}$ in size obtained by ultrasonic dispersion, sedimentation, and centrifugation. Cation exchanges were performed in a saline solution at a concentration of $1 \mathrm{~mol} \mathrm{l}^{-1}$ made from pure $\mathrm{NaCl}$ and deionized water. The solid was

*Corresponding author: Vieillard P, CNRS-IC2MP-UMR 72855 Ave Albert Turpain TSA 51106 86073F POITIERS-POITIERS-Cedex, France, Tel: 33 (0)5 494538 61; Fax: 33 (0)5 494542 41; E-mail: philippe.vieillard@univ-poitiers.fr

Received January 24, 2016; Accepted February 17, 2016; Published February 20, 2016

Citation: Vieillard P, Tajeddine L, Gailhanou H, Blanc P, Lassin A, et al. (2016) Thermo-Analytical Techniques on MX-80 Montmorillonite: A Way to Know the Behavior of Water and its Thermodynamic Properties during Hydration - Dehydration Processes. Pharm Anal Acta 7: 462. doi:10.4172/2153-2435.1000462

Copyright: ( 2016 Vieillard P, et al. This is an open-access article distributed under the terms of the Creative Commons Attribution License, which permits unrestricted use, distribution, and reproduction in any medium, provided the original author and source are credited. 
Citation: Vieillard P, Tajeddine L, Gailhanou H, Blanc P, Lassin A, et al. (2016) Thermo-Analytical Techniques on MX-80 Montmorillonite: A Way to Know the Behavior of Water and its Thermodynamic Properties during Hydration - Dehydration Processes. Pharm Anal Acta 7: 462. doi:10.4172/2153-2435.1000462

Page 2 of 6

dried at $60^{\circ} \mathrm{C}$ for $24 \mathrm{~h}$ in a controlled oven and gently ground in an agate mortar.

The samples used in the current study were all heated to $150^{\circ} \mathrm{C}$ overnight to begin all experiments at similar starting points. Water adsorption and desorption on MX-80 was achieved by exposing approximately $50 \mathrm{mg}$ of dry sample, which was kept in desiccators, to water vapor at a defined partial pressure $\left(\mathrm{P} / \mathrm{P}_{0}\right)$ until equilibrium was reached. Appropriate partial pressures of water vapor used in the measurements correspond to equilibrium vapor pressures above the saturated solutions of 11 selected salts [1]. The lowest relative humidity (RH) (3\%) was obtained with silica gel. Other samples were placed in the desiccator with the highest value of $\mathrm{P} / \mathrm{P}_{0}(0.97)$. After equilibration at $\mathrm{P} / \mathrm{P}_{0}=0.97$, the fully saturated samples were transferred into the primary desiccators for the desorption experiment. The desiccators were kept at a constant temperature $\left(19-20^{\circ} \mathrm{C}\right)$ and atmospheric pressure (approximately $1 \mathrm{~atm}$ ). After equilibrium was reached in adsorption and desorption samples, the amount of water in clay was calculated as a function of temperature by using thermal analysis (TGA-DTA).

Thermal analysis was performed using a simultaneous TGADTA instrument (SDT Q600 from WATERS.A.S in Guyancourt. France). The instrument was temperature calibrated using indium, zinc, and aluminum standards. A weight calibration was performed using standard weights under purged air and a Thermal Analyzer with Thermal Advantage software.

Approximately $50 \mathrm{mg}$ of sample powder was loaded onto a platinum sample pan, and the analysis was performed under two conditions. The first experimental condition was conducted by heating the sample to $1000^{\circ} \mathrm{C}$ at a heating rate of $10^{\circ} \mathrm{C} / \mathrm{min}$ under an air atmosphere; in the second experimental condition, the sample was also maintained under an air atmosphere but was heated to $200^{\circ} \mathrm{C}$ at a constant rate of $5^{\circ} \mathrm{C} /$ min. The rates of heating have been tested preliminary on gypsum and gave good results with experimental observations

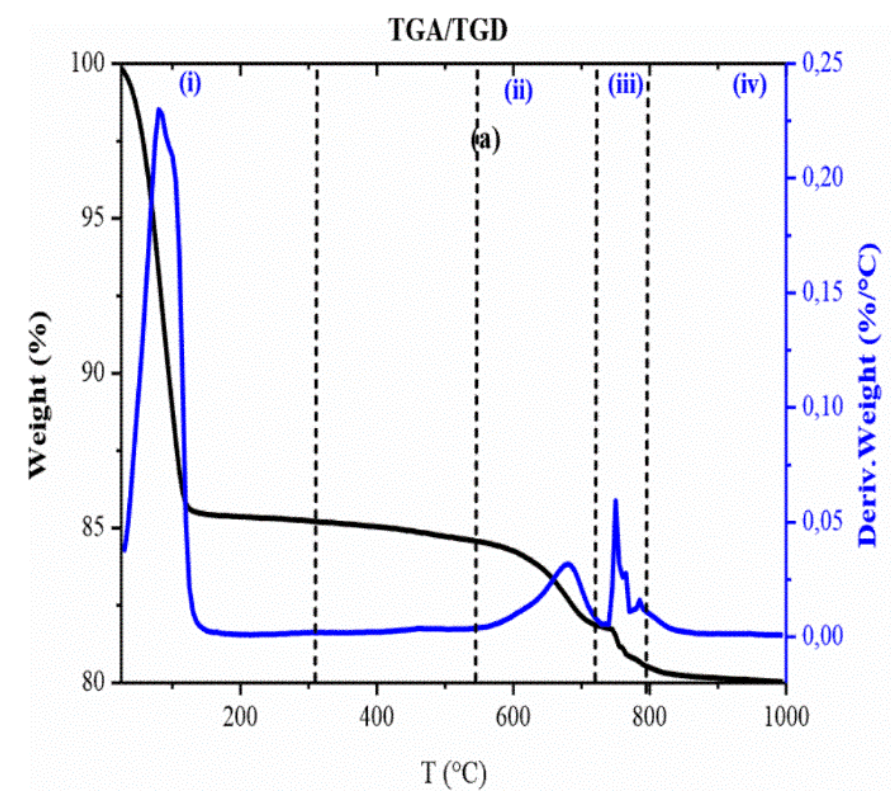

\section{Results and Discussion}

\section{Clay characterization: thermal analysis}

The thermal behavior of the smectite MX- 80 sample was measured with DTA-TGA from ambient temperature to $1000^{\circ} \mathrm{C}$. We used DTA-TGA and their derivatives (DTD-TGD). The DTD-TGD curves exhibited marked inflection points and plateaus, features that were not present in the DTA-TGA curves. Therefore, the DTD-TGD curves more accurately represent different processes than their precursor. The results from TGA/DTG and DTA/ DTD analyses are shown in Figures $1 \mathrm{a}$ and $1 \mathrm{~b}$.

Four main weight loss regions labelled (i), (ii), (iii) and (iv) were observed and correspond respectively - to the dehydration of the external surface and of the interlayer space of the montmorillonites, - to the release of structural $\mathrm{OH}$ from MX-80 montmorillonite, - to the thermodynamic transformation of impurities combined with clay (quartz into tridymite) and at last probably to the rearrangement of high-temperature silica phases associated with the formation of spinel or mullite.

By assuming ideal structural water in the MX-80 montmorillonite and the average structural formula of clay mineral [1], the calculated theoretical water loss is $5.02 \%$ (molar mass of water/molar mass of dehydroxylated MX-80), whereas the experimental amount of structural $(\mathrm{OH})$ calculated from the TGA curve is $4.47 \%$. This gives estimated montmorillonite content in MX-80 smectite is $89.1 \%$ close to the results obtained by RMN analysis (89.5\%).

\section{Thermogravimetric analysis}

The water loss evolution of both adsorption and desorption studies of MX-80, measured by TGA as a function of temperature for different relative humidities, is shown in Figures $2 \mathrm{a}$ and $2 \mathrm{~b}$.

There is no noticeable difference between the adsorption and desorption curves. The dehydration for all the samples (both adsorption and desorption) has already begun at room temperature $\left(25^{\circ} \mathrm{C}\right)$ and the removal of adsorbed water molecules is completed at temperatures

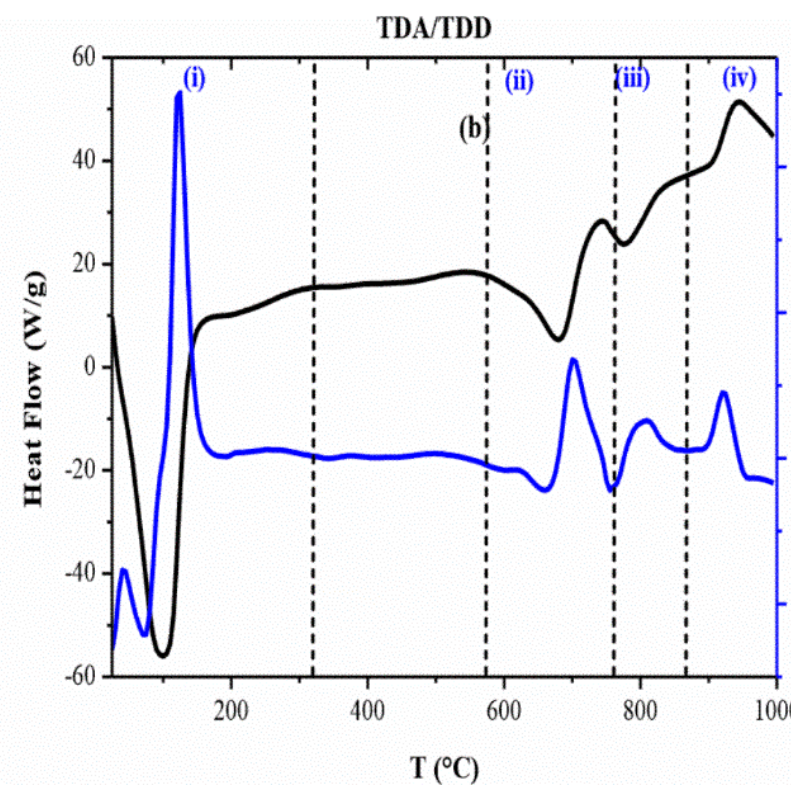

Figure 1: Comparison between thermogravimetry-derivative (a) and differential thermal analysis-derivative (b) curves of smectite $\mathrm{MX}-80$ up to $1000^{\circ} \mathrm{C}$. 
Citation: Vieillard P, Tajeddine L, Gailhanou H, Blanc P, Lassin A, et al. (2016) Thermo-Analytical Techniques on MX-80 Montmorillonite: A Way to Know the Behavior of Water and its Thermodynamic Properties during Hydration - Dehydration Processes. Pharm Anal Acta 7: 462. doi:10.4172/2153-2435.1000462
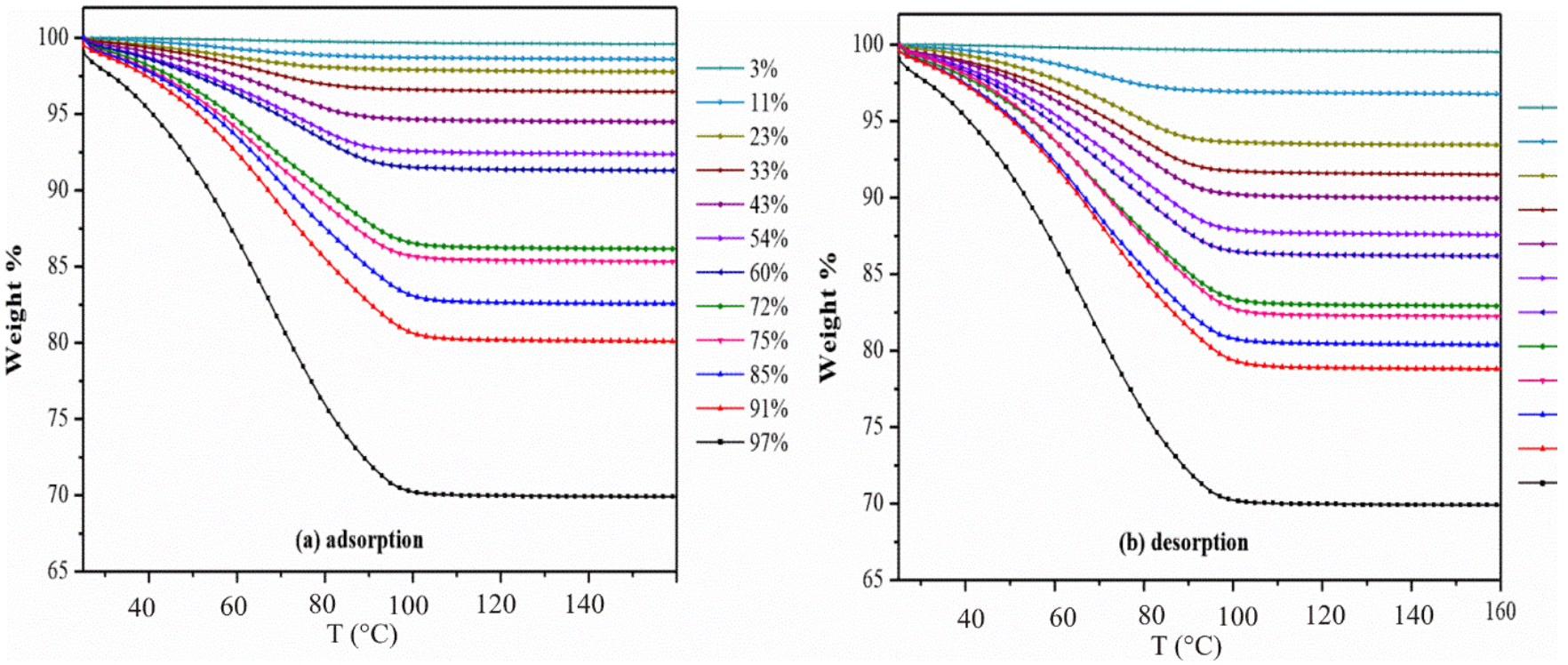

Figure 2: Dehydration TGA measurements of smectite MX-80 equilibrated at different RH in adsorption (a) and desorption (b) processes

below $140^{\circ} \mathrm{C}$ after approximately $2 \mathrm{~h}$. Clay minerals are hydrated with variable amounts of water molecules attached to different sites of hydration. Therefore, we observed a slight change in the inflection of the TGA curves at $\mathrm{T}=40^{\circ} \mathrm{C}$, likely indicating the beginning of the removal of another $\mathrm{H}_{2} \mathrm{O}$ type or multiple, different types. Generally speaking, it is not easy to distinguish between weight loss caused by the removal of adsorbed water molecules and that caused by the other water types by analyzing TGA curves alone. The curves describing the adsorption/ desorption of water vapor can help to interpret and understand the behavior of the TGA curves. The weight loss of water was measured, and the amount of water dehydrated was calculated and expressed as mol $\mathrm{H}_{2} \mathrm{O} / \mathrm{mol}$ dry clay and allows representing the adsorption-desorption isotherm with increasing $\mathrm{RH}$ [referee]. The adsorption-desorption curves of MX-80 reveal the typical features observed for swelling clay minerals with both microporosity and mesoporosity [1].

\section{Differential thermal analysis}

The DTA curves shown in Figure 3 exhibit one low temperature, strongly endothermic peak below $110^{\circ} \mathrm{C}$, corresponding to the evaporation heat of water adsorbed on different sites of clay. The endothermic effect became remarkably strong as the sample humidity increased, meaning that the amount of water adsorbed in all the samples is more pronounced with increased RH. We also observed that the offset temperature range varied slightly with $\mathrm{RH}$, especially for the adsorption study, in which the offset temperature varied from 110 to $130^{\circ} \mathrm{C}$ with increased humidity.

In these curves, the heats obtained during adsorption and desorption are not completely similar; this finding seems to confirm that the adsorption and desorption processes are energetically not reversible.

A further comparison of the results in Figure 3 shows that the curves have irregular shapes, and although the forms of the curves change as a function of sample humidity, for the adsorption results, the most important change noted was the appearance of a plateau between $68^{\circ} \mathrm{C}$ and $88^{\circ} \mathrm{C}$ for $\mathrm{RH}$ of 75 and $80 \%$. However, for the desorption data, a pseudo-plateau was marked between $70^{\circ} \mathrm{C}$ and $90^{\circ} \mathrm{C}$ for $\mathrm{RH}$ of 54 and $60 \%$; thus, at this level, the water which is released was structured water. The interlayer water is perhaps located in the most stable state, and the sodium cation is surrounded by six water molecules.

Similarly to the TGA curves, the analysis of DTA patterns is also complicated because several reactions occur together.

DTA curves are represented by the first derivative of heat flow. Differential thermal analysis derivative curves are compared for adsorption and desorption processes as a function of temperature at various RH conditions. A simple view of the DTD curve shows that DTD more accurately represents the various processes than does DTA.

By analyzing the different peaks [1], the temperature intervals in which different types of water molecules are removed from MX-80 upon heating are evidenced and lead to distinguish three individual regions within which the data display different trends as RH increases. The same effect occurs in both adsorption and desorption curves.

A variation in average temperature of the three phases is observed, both as a function of relative humidity and between the adsorption and desorption curves. We note a higher dehydration temperature for the desorption peaks than the adsorption peaks, which suggests stronger interactions between water and clay in the desorption samples. The dehydration temperature may also be affected by the extent of order; adsorption and desorption reactions cause changes in the geometrical arrangement of water in clays. The water molecules in desorption samples are more organized; this difference is accentuated at low water activity levels, especially for $\mathrm{RH}$ below $43 \%$. The dehydration peaks in the desorption curves are larger than in the adsorption curves, especially for RH below $43 \%$. For higher RH, the behavior of adsorption and desorption peaks became more similar, which can be explained by the amount of water present in the samples.

\section{Thermodynamic considerations}

The amount of heat transferred between the system and the surroundings is related to the quantity and change in the enthalpy of complete phase change from initial onset to completion. $\Delta \mathrm{H}_{\text {tot' }}$ which represents the difference between the enthalpy of the system at the beginning of the reaction and that at the end of the reaction, is a combination of several energy types involved during heating and is 
Citation: Vieillard P, Tajeddine L, Gailhanou H, Blanc P, Lassin A, et al. (2016) Thermo-Analytical Techniques on MX-80 Montmorillonite: A Way to Know the Behavior of Water and its Thermodynamic Properties during Hydration - Dehydration Processes. Pharm Anal Acta 7: 462. doi:10.4172/2153-2435.1000462

Page 4 of 6
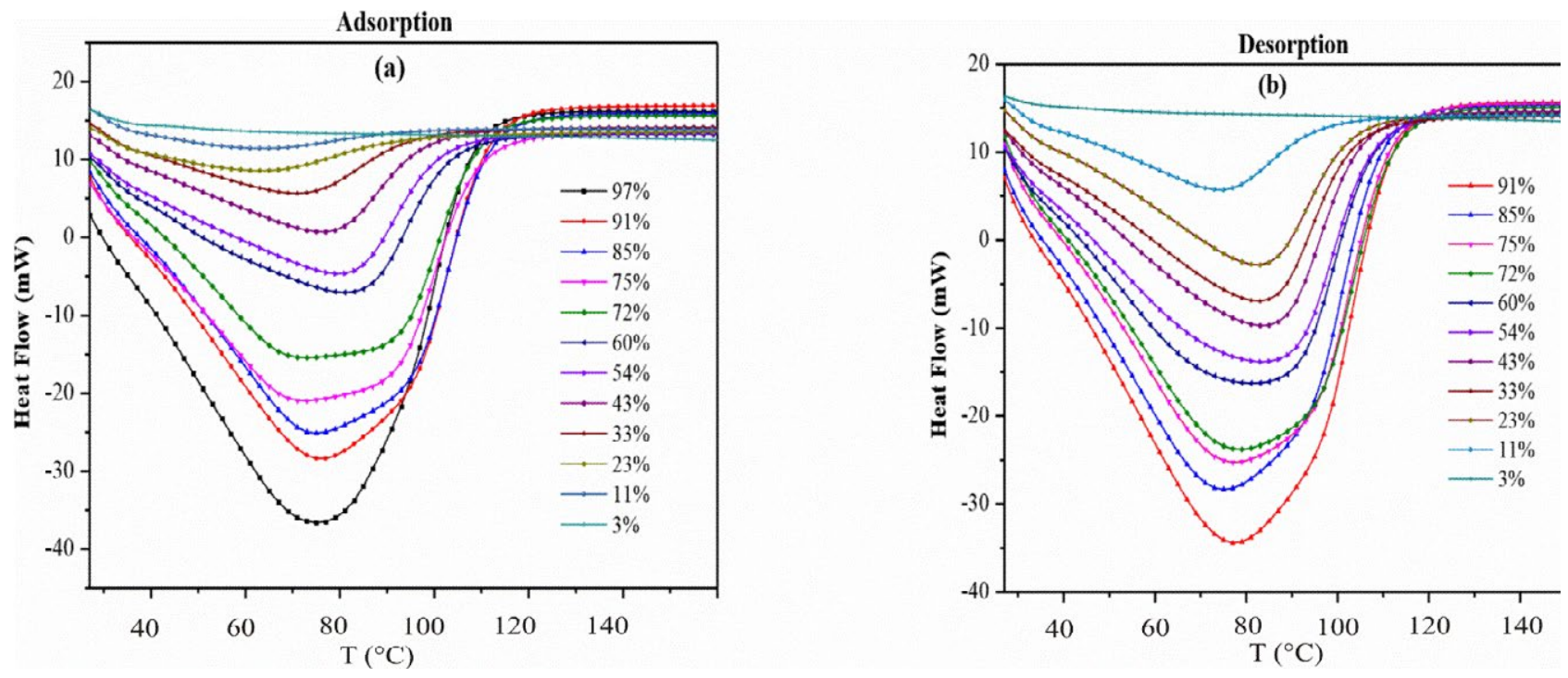

Figure 3: Differential thermal analysis (DTA) curves of smectite MX-80 equilibrated at different RH in adsorption (a) and desorption (b) processes.

determined directly from the peak area of the DTA curves and from an analysis of the total water loss responsible for the peak area.

To determine the energy involved in the dehydration reactions of MX-80, we used methods reviewed by Barshad [19] who reported that the dehydration reaction of minerals, $\Delta \mathrm{H}_{\text {tot }}$, occurs in three steps:

1. The rise in temperature of the hydrated mineral from temperature $T_{1}$ to temperature $T_{2}$, at which dehydration occurs. This transformation involves energy, $\Delta \mathrm{H}_{1}$ absorbed by clay during heating from $T_{1}$ to $T_{2}$, is equal to the integral of the heat capacities of dehydrated montmorillonite and liquid water.

2. The dehydration of water as "liquid" water (l) accompanied by changes in the mineral itself and characterizes the dehydration enthalpy, $\Delta \mathrm{H}_{2}$.

3. The conversion of "liquid" water to "gaseous" water at $\mathrm{T}_{2}$. This transformation characterizes, the enthalpy of vaporization of water, $\Delta \mathrm{H}_{3}$, and represents the difference between the heat capacities measured for both liquid (l) and gaseous water (g) phases at a known temperature, expressed by the following relation.

By assuming an ambient temperature $\mathrm{T}_{1}=25^{\circ} \mathrm{C}$, the knowledge of - the temperature $T_{2}$ at which the sample begins to dehydrate, - the heat capacities of dehydrated montmorillonite [16] and liquid water, -the enthalpy of vaporization of water at a temperature $T_{2}$ and $-\Delta H_{\text {tot }}$ obtained from the peak area of the DTA curves, contribute together to the computation of dehydration enthalpy of smectite at $\mathrm{T}_{2}$ by using the thermochemical cycles $[1,19]$ :

$$
\Delta \mathrm{H}_{\text {dehy }}=\Delta \mathrm{H}_{2} / \mathrm{n}=\left(\Delta \mathrm{H}_{\text {tot }}-\Delta \mathrm{H}_{1}-\mathrm{n}^{\star} \Delta \mathrm{H}_{3}\right) / \mathrm{n}
$$

The $\Delta \mathrm{H}_{\text {dehy }}$ values with an associated error of two standard deviations of the mean, for both adsorption and desorption systems are represented in Figure $4 \mathrm{a}$.

The most interesting feature of the dehydration enthalpy values for both studies (adsorption and desorption) is the manner in which the values change with increasing water content. The low dehydration enthalpies at high humidities reflect the fact that the last water molecules to be lost are more tightly bound and indicate that the molecular environment of $\mathrm{H}_{2} \mathrm{O}$ in these samples is energetically close to that of $\mathrm{H}_{2} \mathrm{O}$ in bulk.

The $\Delta \mathrm{H}_{\text {dehy }}$ values of the adsorption and desorption curves show the same type of variations with increasing water content in samples except that the speed of variations is not the same in both processes. These variations are believed to result from the manner in which the interlayer expansion and contraction occur in conjunction with the movement of the exchangeable ions in and out of the hexagonal cavities in the oxygen surfaces, as outlined previously.

Barshad [19] showed that in adsorption and desorption processes, the presence of a minimal $\Delta \mathrm{H}_{\text {dehy }}$ values in the water content ranging between 1 and 2 mole per mole of clay is explained by the manner with which the water reacts with montmorillonite depending of the water content.

However, the process described by Barshad [19] did not correlate with the data obtained in our DTA curves [1]. This result confirmed that water reacts with exterior surfaces and interlayer spaces of montmorillonite at very low water contents.

We also calculated the enthalpy of the formation of water relative to dehydrated MX-80, $\Delta \mathrm{H}_{\mathrm{f}}^{\circ}\left(\mathrm{H}_{2} \mathrm{O}\right)$, for both adsorption and desorption. These enthalpies are important reference values for thermodynamic analyses. To calculate the enthalpy of the formation of sorbed water, $\Delta \mathrm{H}_{\mathrm{f}}^{\circ}\left(\mathrm{H}_{2} \mathrm{O}\right)_{\text {sorb }}$, an estimate of the integral dehydration enthalpies of MX-80, is required. This estimate is based on the available data for dehydration enthalpies. The enthalpies of the formation of water from MX-80 are plotted as a function of mole water per mole of dry clay in Figure $4 \mathrm{~b}$.

As shown in Figure 4b, at high humidity, the enthalpy of the formation of water during the adsorption process tends to be closer to the standard enthalpy of the formation of liquid water. The similarity of these values indicates that only the first monolayer of water adsorbs strongly, as chemisorbed water. In terms of its thermodynamic properties, the behavior of $\mathrm{H}_{2} \mathrm{O}$ in excess of the first monolayer is simply liquid water. However, during desorption, we do not observe great variation with an increased quantity of water, which confirms 
Citation: Vieillard P, Tajeddine L, Gailhanou H, Blanc P, Lassin A, et al. (2016) Thermo-Analytical Techniques on MX-80 Montmorillonite: A Way to Know the Behavior of Water and its Thermodynamic Properties during Hydration - Dehydration Processes. Pharm Anal Acta 7: 462. doi:10.4172/2153-2435.1000462

Page 5 of 6
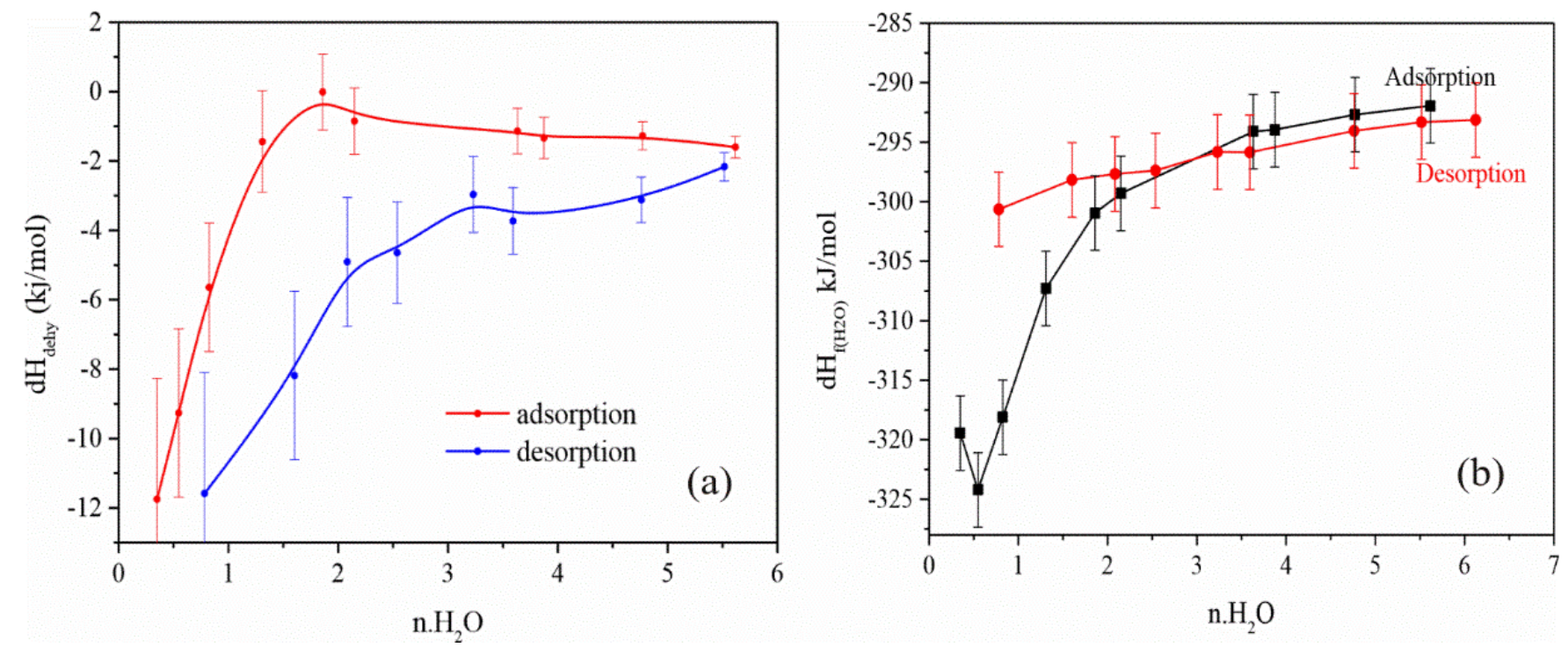

Figure 4: (a) $\Delta \mathrm{H}^{\circ}$, curves for water dehydrated from smectite MX-80 in adsorption and desorption processes; (b) $\Delta \mathrm{H}^{\circ}{ }_{\mathrm{f}}\left(\mathrm{H}_{2} \mathrm{O}\right)_{\text {sorb }}$ curves of water formation for $\mathrm{MX}-80$ in adsorption and desorption.

that this water is more stable and behaves in the same manner despite the increased amount of water.

\section{Conclusion}

Thermal analysis is a well-established set of techniques for obtaining qualitative and quantitative information. In this study, analyses of the experimental data, in combination with previously reported data, yielded important information about the dehydration process of MX80 bentonite; to obtain this information, the interpretation of the curves must be performed with great attention. TGA curves were used to describe the adsorption and desorption of water vapor by MX-80 bentonite. As expected, the adsorption-desorption of water vapor exhibited hysteresis for all relative pressure ranges investigated in this study. Moreover, we have demonstrated that DTA curves are more effectively studied using the first derivative of heat flow. Three individual regions within the data display different trends as $\mathrm{RH}$ increases. The same effect occurs in both adsorption and desorption curves. We also found that the enthalpy of dehydration for both adsorption and desorption is independent of the content of water present in the sample; the enthalpy of dehydration is high for the first molecules adsorbed, and only the first monolayer of water adsorbs strongly.

The results presented here represent the key data that are necessary to begin the elaboration of a quantitative model able to describe and predict the thermodynamic transfer of water between mesopores and interlayer spaces as a function of relative humidity. The next stage will be to separate the energies based on external surface, the energies of layer hydration, and the energy due to swelling.

\section{References}

1. Tajeddine L, Gailhanou H, Blanc P, Lassin A, Gaboreau S, et al. (2015) Hydration-dehydration study behavior, and thermodynamlic properties of MX80 montmorillonite studied using thermal analysis. Thermochimica Acta 604: 83-93.

2. Ferrage E, Lanson B, Sakharov BA, Drits VA (2005) Investigation of smectite hydration properties by modeling experimental X-ray diffraction patterns: Part I. Montmorillonite hydration properties. Am Mineral 90: 1358-1374.
3. Sato T, Wanatabe T, Otsuka R (1992) Effect of layer charge, charge location, and energy change on expansion properties of dioctahedral smectites. Clays Clay Miner 40: 103-113.

4. Berend I, Cases JM, Francois M, Uriot JP, Michot L, et al. (1995) Mechanism of adsorption and desorption of water vapor by homoionic montmorillonites: 2 .

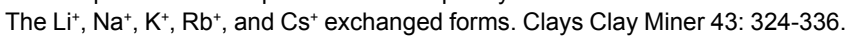

5. Cases JM, Berend I, Besson G, Francois M, Uriot JP, et al. (1992) Mechanism of adsorption and desorption of water vapor by homoionic montmorillonite. 1. The sodium-exchanged form. Langmuir 8: 2730-2739.

6. Guven N (1992) Molecular aspects of aqueous smectite suspensions. Clay Min Soc 4: 2-79.

7. Salles F, Douillard JM, Denoyel R, Bildstein O, Jullien M, et al. (2009) Van Damme, $\mathrm{H}$. Hydration sequence of swelling clays: Evolutions of specific surface area and hydration energy. J Colloid Interface Sci 333: 510-522.

8. Laird DA (1999) Layer change influences on the hydration of expandable 2:1 phyllosilicates. Clays and Clay Minerals 47: 630-636.

9. Laird DA, Shang C, Thompson M (1995) Hysteresis in Crystalline Swelling of Smectites. Journal of Colloid and Interface Science 171: 240-245.

10. Salles F, Beurrois I, Bildstein O, Julien M, Raynal J (2008) A calorimetric study of mesoscopic swelling and hydration sequence in solid Na-montmorillonite. Applied Clay Science 39: 186-201.

11. Salles F, Bildstein O, Douillard JM, Julien M, Raynal J (2010) On the Cation Dependence of Interlamellar and Interparticular Water and Swelling in Smectite Clays. Langmuir 26: 5028-5037.

12. Xu W, Johnston CT, Parker $P$, Agnew SF (2000) Infrared study of water sorption on Na-, Li-, Ca- and Mg-exchanged (SWy-1 AND SAz-1) montmorillonite. Clays and Clay Miner 48: 120-131.

13. Cases JM, Bérend I, François M, Uriot JP, Michot L (1997) Mechanism of adsorption and desorption of water vapor by homoionic montmorillonite: 3 , The $\mathrm{Mg}\left(\right.$ Super $\left.2^{+}\right), \mathrm{Ca}\left(\right.$ Super $\left.2^{+}\right)$, and $\mathrm{Ba}\left(\right.$ Super $2^{+}$) exchanged forms. Clays and Clay Miner 45: 8-22.

14. Khalfi A, Blanchart $P$ (1999) Desorption of water during the drying of clay minerals. Enthalpy and entropy variation. Ceram Int 25: 409-414.

15. Dios Cancela G, Huertas FJ, Romero Taboada E, Sánchez-Rasero F Hernández Laguna A (1997) Adsorption of water vapor by homoionic montmorillonites. Heats of adsorption and desorption. J Colloid Interface Sci 185: 343-354. 
Citation: Vieillard P, Tajeddine L, Gailhanou H, Blanc P, Lassin A, et al. (2016) Thermo-Analytical Techniques on MX-80 Montmorillonite: A Way to Know the Behavior of Water and its Thermodynamic Properties during Hydration - Dehydration Processes. Pharm Anal Acta 7: 462. doi:10.4172/2153-2435.1000462

Page 6 of 6

16. Gailhanou H, Blanc P, Rogez J, Mikaelian G, Kawaji H, et al. (2012) Thermodynamic properties of illite IMt-2, smectite MX-80 and beidellite SBId-1 by calorimetric methods: Enthalpies of formation, heat capacities, entropies and Gibbs free energies of formation. Geochim Cosmochim Acta 89: 279-301.

17. Gailhanou H, van Miltenburg JC, Rogez J, Olives J, Amouric M, et al. (2007) Thermodynamic properties of anhydrous smectite MX-80, illite IMt-2 and mixedlayer illite-smectite ISCz-1 as determined by calorimetric methods. Part I: Heat capacities, heat contents and entropies. Geochim Cosmochim Acta 71 5463-5473.

18. ANDRA Dossier 2005_Argile; Andra, France: 2005.

19. Barshad I (1952) Temperature and heat of reaction calibration of the differential thermal analysis. Amer Mineralogist 37: 667-694. 